\title{
Silent Type li Truncus Arteriosus Diagnosed at the Age of 18-years in a Ugandan Male
}

\section{SENAI Goitom SEREKE ( $\nabla$ nayhersen@gmail.com )}

Makerere University Faculty of Medicine: Makerere University College of Health Sciences https://orcid.org/0000-0001-8190-2070

\section{Hamdi Mohamed Isse}

Makerere University Faculty of Medicine: Makerere University College of Health Sciences

\section{Tamale Jaffar}

Makerere University Faculty of Medicine: Makerere University College of Health Sciences

\section{Felix Bongomin}

Gulu University Faculty of Medicine

\section{Case Report}

Keywords: Conotruncal cardiac defects, ventricular septal defect, truncus arteriosus

Posted Date: January 27th, 2021

DOI: https://doi.org/10.21203/rs.3.rs-152318/v1

License: (1) (1) This work is licensed under a Creative Commons Attribution 4.0 International License. Read Full License 


\section{Abstract}

Background: Persistent truncus arteriosus $(T A)$ is a rare congenital heart condition with reported incidence of $1.2 \%$ among all congenital heart malformations. Majority of patients with TA die early in childhood due to complications such as heart failure.

Case presentation: An 18-year-old adult with unsuspected congenital heart disease since birth, not detected in childhood. Six months prior to his presentation, he complained of easy fatigability and paroxysmal nocturnal dyspnea. Chest radiography demonstrated normal heart size and electrocardiogram showed biventricular hypertrophy. Echocardiograph showed truncus arteriosus type II with large outlet ventricular septal defect. The patient was put on medical therapy including bed rest, fluid restriction and then surgical correction was done. The patient's symptom improved after the surgical correction.

Conclusion: TA is a rare, serious congenital heart defect that can be detected in prenatal period by routine ultrasound screening. It is also very rare for TA to be silent and reach adulthood without clinical manifestation and a diagnosis.

\section{Background}

The truncus arteriosus (TA) is a rare conotruncal cardiac defect which consists in the persistence of the physiologic common arterial trunk (1). It is reported to be 1.1 to $1.3 \%$ of all congenital cardiac defects (2). The ascending aorta and main pulmonary trunk arise from the base of the heart without being differentiated, as a result, there is a single large vessel that overhangs either on a single ventricle or extends across the two ventricles (1).

TA is an uncommon form of congenital heart disease in older children or adults, although it is seen occasionally in young adults who survive past the age of 20 (3). In this report, we describe a case of TA diagnosed in an adult.

\section{Case Presentation}

An 18-year-old boy, presented with complaints of intermittent chest pain and paroxysmal nocturnal dyspnea four months. He had no complaint of cough, fever or joint pain. His growth and physical activities were normal. His mother could not remember of any sickness during her pregnancy and reported she did not attend antenatal care. There was no family history of cardiac illness reported. He is the second born in a family of four, the rest of the siblings are healthy.

Examination revealed a young man, normal weight and height for his age (Height $174 \mathrm{~cm}$, Weight $68 \mathrm{~kg}$ ). The pulse rate was $88 \mathrm{bpm}$ and regular with blood pressure of $100 / 50 \mathrm{~mm} \mathrm{Hg}$. The respiratory rate was 16 and oxygen saturation in room air was $96 \%$. Apex beat was at $6^{\text {th }}$ intercostal space, and a pansystolic murmur was heard with maximal intensity at the left sternal edge. Auscultation at the second left 
intercostal space parasternal revealed a loud, single second heart sound. The chest was clear bilaterally and abdominal examination was unremarkable. No pedal edema was noted.

Chest radiography revealed a normal heart shadow without cardiomegaly and equal distribution of pulmonary vascularity in both lungs (Figure 1). An electrocardiogram (ECG) showed a normal sinus rhythm with ventricular wall hypertrophy (Figure 1).

Transthoracic echocardiography showed atrial situs solitus with levocardia. Concordant Atrioventricular connections with $D$ looped ventricles were noted. There was septal and lateral ventricular wall increased thickness with no significant enlargement of the heart chambers. Both ventricles are drained by a single vessel (persistent truncus trunk) via a large outlet ventricular-septal defect (VSD). The trunk gives off a short main pulmonary artery posteriorly and continues as left sided aortic arch. Branching pulmonary artery arise separately from posterior aspect. Left pulmonary artery- $19 \mathrm{~mm}$, right pulmonary artery- $24 \mathrm{~mm}$, non-obstructive sub truncal membrane in left ventricular outflow tract. The truncal valve is bicuspid and there is mild stenosis of the truncal valve with Pressure gradient- $53 / 33 \mathrm{mmHg}$. Mild regurgitation of the truncal valve was also noted. There was mild tricuspid regurgitation, Pressure gradient- $11.4 \mathrm{mmHg}$ but normal mitral valve. No patent ductus arteriosus, atrial septal defect or coarctation of the aorta. There was biventricular hypertrophy and large outlet VSD (Figure 2-5).

The lesions were surgically repaired. There were no post repair complications. The patient's symptom dramatically improved after the surgical correction.

\section{Discussion}

TA is classified into four anatomic types depending on the presence or absence of the main pulmonary trunk or arteries and their origins if present. In type II TA, both pulmonary arteries arise together from the posterior wall of the trunk (4). Our patient had a type II TA.

The patient presented with an on and off chest pain, paroxysmal nocturnal dyspnea and easy fatigability. The patient's cardiac symptoms started very late in adolescence, which is very uncommon. The metabolic and physical growth of the body is assumed to the reason as to why it manifests as late as adolescence $(5,6)$.

The plain chest radiograph in this patient showed an even distribution in the vascularity on both sides. Grainger has asserted that the volume of the lung deprived of its pulmonary artery is smaller than the contralateral normal lung and is usually of equal, or even increased radiodensity (7). In this presented case, the lung perfusion of both lungs seems to be optimal.

Echocardiography has revolutionized the diagnosis of congenital anomalies without an added risk of radiation to patients. The B-mode, M-mode and color mapping are sufficient in most cases for the diagnosis of TA and further recommendations for intervention (8). TA in our patient was diagnosed by echocardiography. 
Cardiac magnetic resonance imaging, Computed angiography of the heart and great vessels and cardiac catheterization are used to evaluate the systemic- pulmonary collaterals, coronary arteries and presurgical correction (9).

There is no consensus as to when and who treat in cases of truncus arteriosus that are detected in adulthood. So far it is case based management in which some were managed with successful surgical repair and some others medical therapy alone $(6,10)$. There are very few reported cases of TA diagnosed in adulthood in the literature.

TA is an uncommon form of congenital heart disease in older children or adults, although it is seen occasionally in young adults who survive past the age of 20 (3). The patient was 18 years old at the time of diagnosis. Moreover, his childhood and adolescence periods were uneventful and that makes it very unusual.

\section{Conclusion}

TA is a rare, serious congenital heart defect of various causes and it can be detected in prenatal period by routine ultrasound screening. Echocardiography plays the biggest role in the diagnosis and follows up of patients with TA. It is also very uncommon for TA to be silent and reach adulthood without clinical manifestation and a diagnosis. Hence high index of suspicion is important to diagnose this rare entity.

\section{Declarations}

\section{Consent to participate}

The patient provided an informed written consent to participate in the study of their child's case.

\section{Consent for publication}

The patient provided an informed written consent for this case to be published in a peer-reviewed journal.

\section{Availability of data and materials}

The information used and/or analyzed during this case report is available from the corresponding author on reasonable request.

\section{Competing interests}

The authors declare that they have no conflict of interests.

\section{Funding}

No funding 


\section{Authors' contribution}

SG, HM, TJ, FB made a significant contribution to the work reported, whether that is in the conception, study design, execution, acquisition of data, analysis and interpretation, or in all these areas; took part in drafting, revising or critically reviewing the article; gave final approval of the version to be published; have agreed on the journal to which the article has been submitted; and agree to be accountable for all aspects of the work.

\section{Author's information}

1. SG, MBChB (OSMD), MMed Radiology (MAKCHS)

2. HM, MBChB (Benadir University), MMed Radiology (MAKCHS)

3. TJ, MBChB (KIU), MMed Radiology (MAKCHS)

4. FB, MBChB (Gulu), MSc (Manchester)

\section{Acknowledgements}

We would like to acknowledge, the patient and his parents, the staff of radiology department of Mulago National Referral Hospital, the cardiothoracic surgery ward, for they actively supported the process of data collection and patient follows up.

\section{References}

1. Poaty H, Pelluard F, André G, Maugey-Laulom B, Carles D. Truncus arteriosus communis: report of three cases and review of literature. Afr Health Sci. 2018;18(1):147-56.

2. Valle C, Hadley M. Truncus Arteriosus. In: DeFaria Yeh D, Bhatt A, editors. Adult Congenital Heart Disease in Clinical Practice. Cham: Springer International Publishing; 2018. p. 319-30.

3. Abid D, Daoud E, Ben Kahla S, Mallek S, Abid L, Fourati H, et al. Unrepaired persistent truncus arteriosus in a 38-year-old woman with an uneventful pregnancy. Cardiovasc J Afr. 2015;26(4):e6-e8.

4. Collett RW, Edwards JE. Persistent truncus arteriosus; a classification according to anatomic types. Surg Clin North Am. 1949;29(4):1245-70.

5. Espínola-Zavaleta N, Muñoz-Castellanos L, González-Flores R, al. e. Common truncus arteriosus in adults. Arch Cardiol Mex. 2008;78(2):210-6.

6. Peter I, Oladele D, Kefas G, Kayode $\mathrm{O}$, Iseko I. Challenges with managing delayed presentation of persistent truncus arteriosus with torrential pulmonary blood flow in a Resource-Limited setting. Journal of Cardiovascular Echography. 2019;29(2):75-7.

7. Grainger RG. The pulmonary circulation: the radiology of adaptation. Clin Radiol. 1985;36(2):103-16.

8. Guenther F, Frydrychowicz A, Bode C, Geibel A. Persistent truncus arteriosus: a rare finding in adults. European Heart Journal. 2009;30(9):1154-. 
9. Koplay M, Cimen D, Sivri M, Güvenc O, Arslan D, Nayman A, et al. Truncus arteriosus: Diagnosis with dual-source computed tomography angiography and low radiation dose. World J Radiol. 2014;6(11):886-9.

10. Ivanov Y, Mykychak Y, Fedevych O, Motrechko O, Kurkevych A, Yemets I. Single-centre 20-year experience with repair of truncus arteriosus. Interact Cardiovasc Thorac Surg. 2019;29(1):93-100.

\section{Figures}

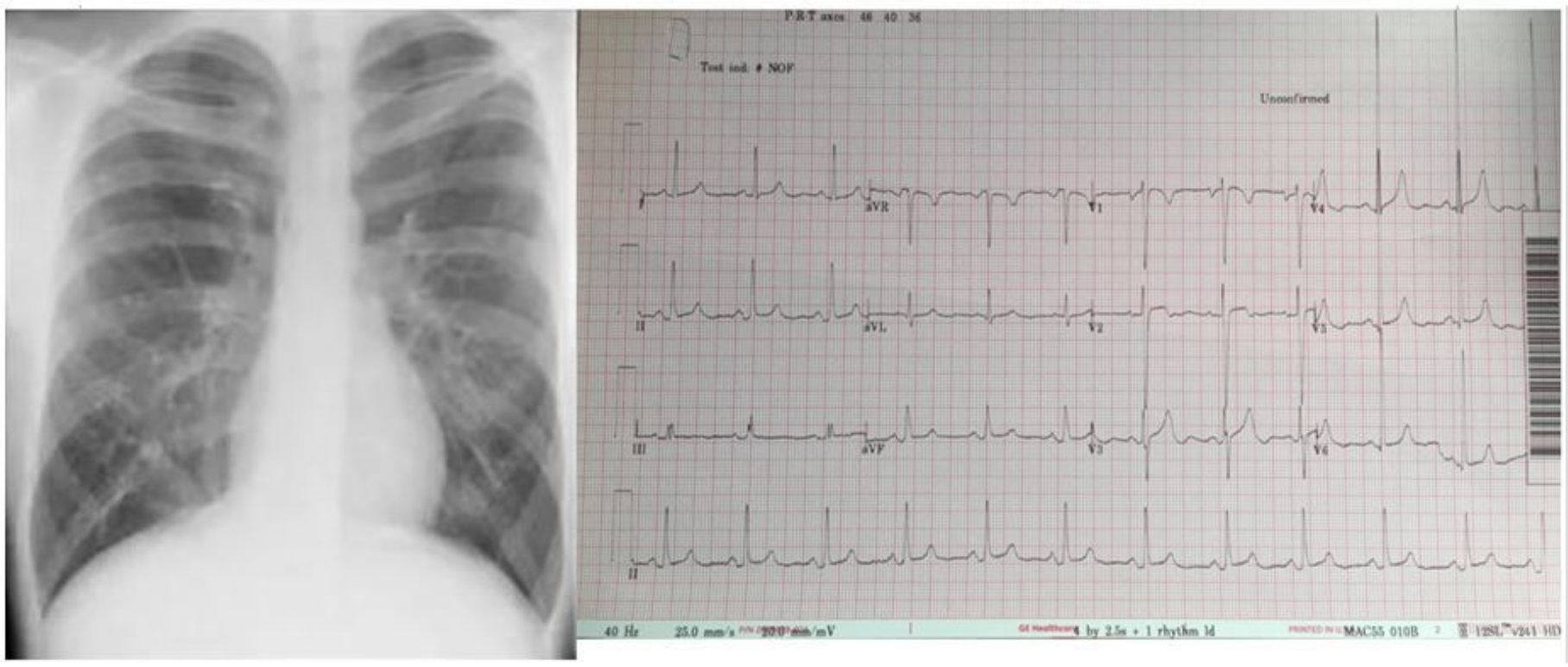

\section{Figure 1}

Frontal chest radiograph demonstrated normal heart contour and size with equal pulmonary vascular distribution. ECG demonstrated sinus rhythm with Biventricular hypertrophy (in leads V1-V6)

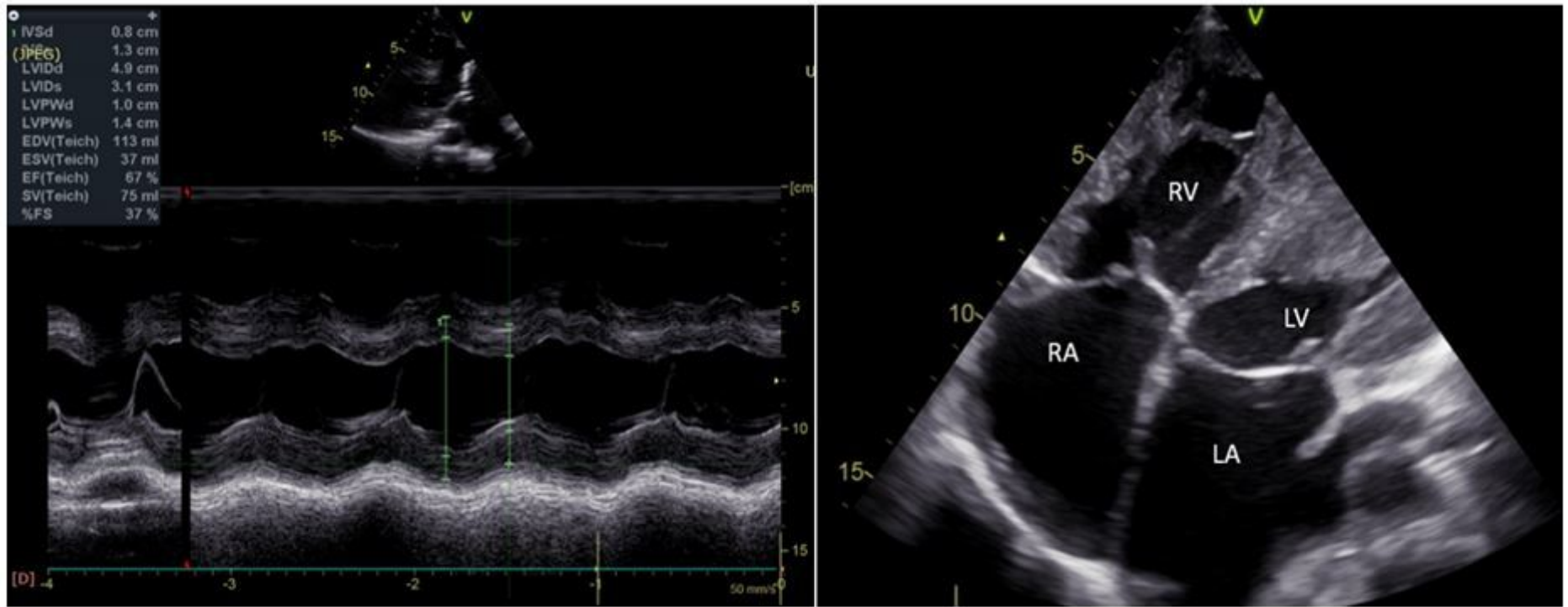




\section{Figure 2}

M-mode (left) showed normal systolic function of the heart with significant posterior wall hypertrophy. Apical four chambered view (right) demonstrated septal and lateral walls hypertrophy.

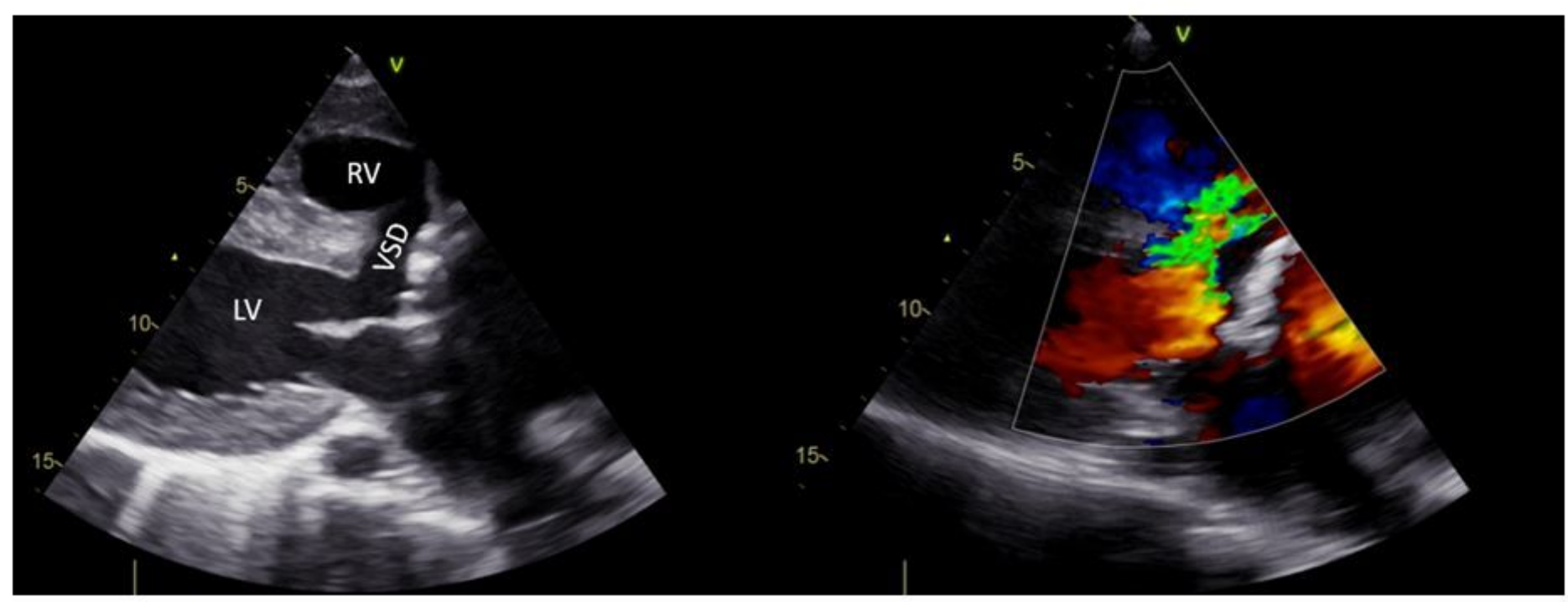

\section{Figure 3}

Transthoracic echocardiography parasternal long axis showed large outlet VSD with Left-Right shunt.

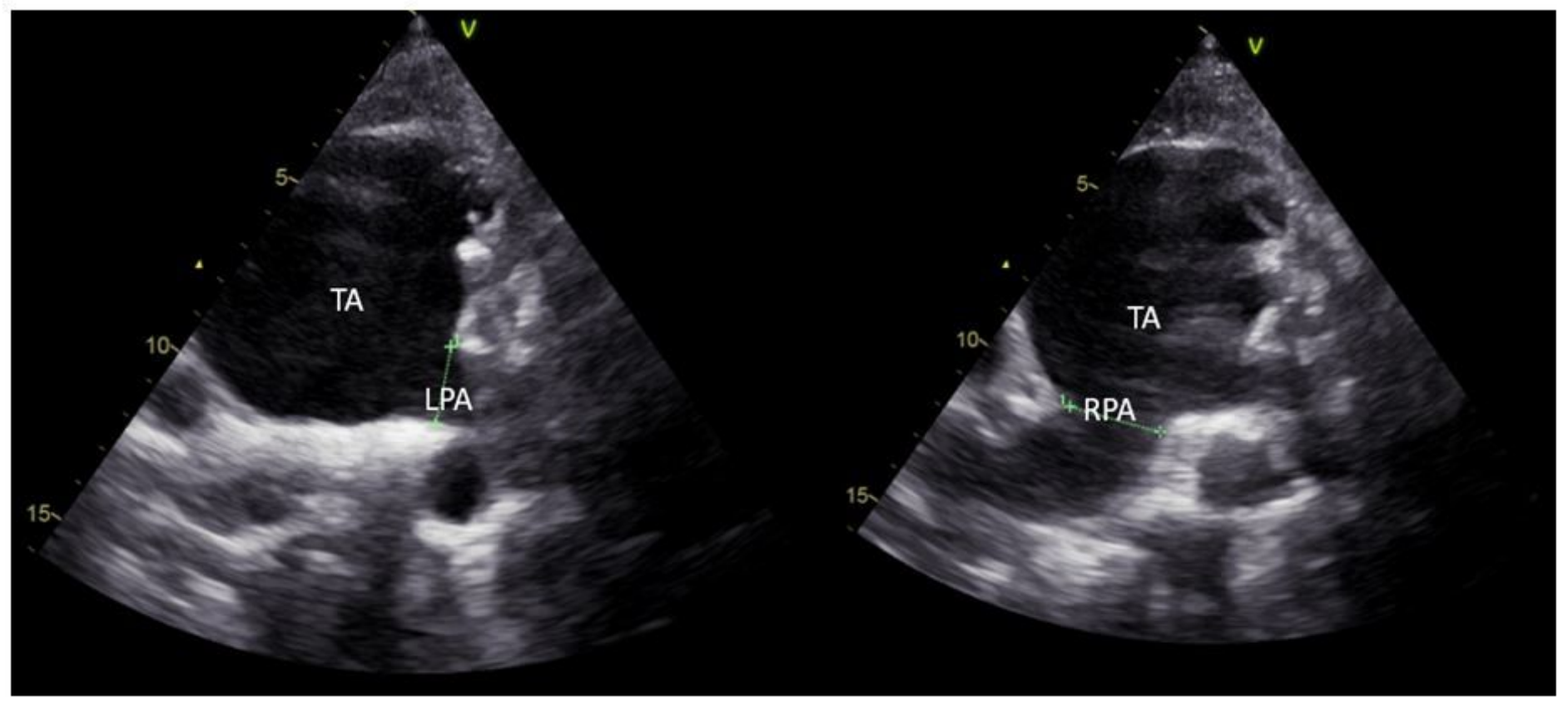

Figure 4

Parasternal short axis demonstrating both LPA and RPA arising separately from posterior aspect of the truncus. 


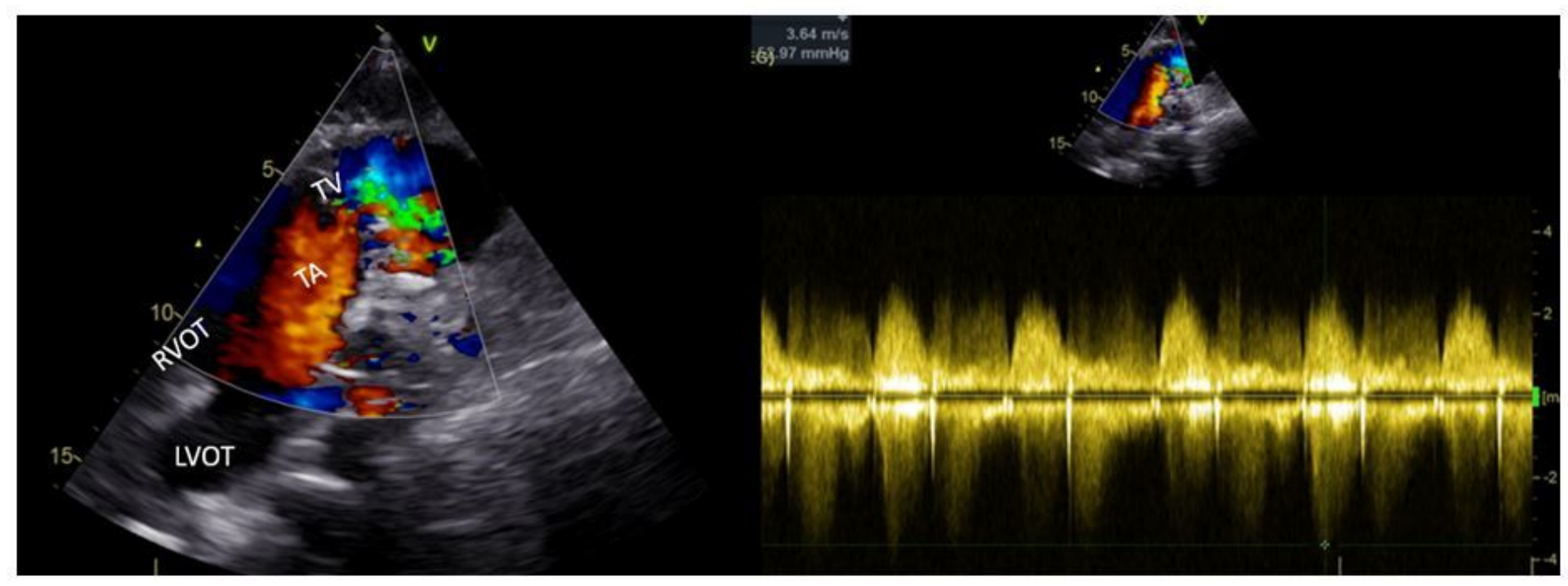

\section{Figure 5}

parasternal long axis demonstrating truncal valve (TV) stenosis and mild regurgitation with high pressure gradient at the truncal valve on pulsed wave Doppler. 